\title{
Designing a Low Cost Electrospinning Device for Practical Learning in a Bioengineering Biomaterials Course
}

\author{
R.D. Velasco Barraza1, A.S. Álvarez Suarez², L.J. Villarreal Gómezz ${ }^{1,2}$, J.A. Paz González , A.L. \\ Iglesias $^{1}$, R. Vera Graziano ${ }^{3}$ \\ ${ }^{1}$ Escuela de Ciencias de Ingeniería y Tecnología, Universidad Autónoma de Baja California, Tijuana \\ ${ }^{2}$ Facultad de Ciencias Químicas e Ingeniería, Universidad Autónoma de Baja California, Tijuana, México. \\ ${ }^{3}$ Instituto de Investigación en Materiales, Universidad Nacional Autónoma de México, Distrito Federal, México.
}

\section{ABSTRACT}

The electrospinning device is used in the biomaterials research field nowadays for fabricating nanofibers that can be used for manufacturing artificial skin and muscular tissue, blood vessels (vascular grafts), orthopedic components (bones, cartilages, and ligaments/tendon), and peripheral or central nervous system components. Electrospun nanofibers act as ideal scaffolds for tissue engineering and drug delivery systems because they can mimic the functions of native extracellular matrices. A low cost electrospinning device was designed and built for undergraduate practical learning in the Biomaterials course in the area of Bioengineering at Universidad Autónoma de Baja California, México. The methodology includes 3D CAD designing, manufacturing of the acrylic cabinet, different collectors and the fabrication of poly (vinyl alcohol) nanofibrous scaffolds, in order to validate the functionality of the electrospinning system. The prototype is an affordable device; its cost is $95 \%$ less than the laboratory commercial devices.

Keywords: biomaterials, bioengineering, electrospinning, SOLIDWORKS models, nanofibers.

Correspondencia:

Luis Jesús Villarreal Gómez

Facultad de Ciencias Químicas e Ingeniería, Universidad Autónoma de Baja California, Blvd. Universitario No. 1000 C.P. 22550, Tijuana, México.

Correo electrónico: luis.villarreal@uabc.edu.mx
Fecha de recepción: 25 de junio de 2015

Fecha de aceptación: 19 de octubre de 2015 


\section{RESUMEN}

El dispositivo de electrohilado es actualmente empleado en la investigación de biomateriales, utilizado para sintetizar nanofibras que ofrecen un potencial para la manufactura de piel artificial y tejido muscular, vasos sanguíneos (implantes vasculares), componentes ortopédicos (hueso, cartílago y tendones/ligamentos) y componentes del sistema nervioso central y periférico. Las nanofibras producidas por electrohilado pueden ser usadas como andamios ideales para ingeniería de tejidos y liberación controlada de fármacos debido a que mimetizan las funciones de la matriz extracelular. El dispositivo de electrohilado de bajo costo fue diseñado y construido para al aprendizaje practico de estudiantes de licenciatura en la asignatura de Biomateriales de la carrera de Bioingeniería. La metodología incluye diseños CAD 3D, manufactura del gabinete de acrílico, diferentes colectores y fabricación de los andamios de nanofibras de Poli (vinil alcohol) para validar la correcta funcionalidad del sistema de electrohilado. El prototipo es un dispositivo accesible económicamente, su costo es un $95 \%$ más barato que los dispositivos de tipo comercial.

Palabras clave: biomateriales, bioingeniería, electrohilado, modelos en SOLIDWORKS, nanofibras.

\section{INTRODUCTION}

Bioengineering is a multidisciplinary field that creates and innovates new strategies, which revolutionize our life style. Commonly known as a "technology based on biology" bioengineering has had a direct effect to the world. Through the breakthrough of bioengineering in medicine, for example, antibiotics, scientists are creating insulin using bacteria in the comfort and safety of their labs [1].

David A. Tirrell (2012) [2], from the National Science Foundation (NSF), proclaimed, "Biomaterials is a rapidly emerging component of the materials research community". Research in this area covers a broad range of activities that include the development of materials used for (1) delivery of therapeutic and diagnostic agents, (2) construction of medical devices that must be compatible with the living systems in which they are in contact and (3) scaffolds for tissue engineering and regenerative medicine applications. Other aspects in this field involves exploiting mimicry of, inspiration by, or co-opting of biological systems to enable creation of novel functional Biomaterials.
Undergraduate Bioengineering students must learn chemistry, physics, mathematics and engineering. They must be proficient in several disciplines in order to understand how materials are fabricated, characterized and employed. Since students enter the biomaterials research field with a variety of backgrounds, such as chemistry, chemical engineering, mechanical engineering, pharmaceutical chemistry, biology, or computer science, they lack a shared set of core ideas and information [2].

Electrospinning has proved being a useful alternative for tissue regeneration, it is a versatile and inexpensive technique for manufacturing polymeric scaffolds that mimic the extracellular matrix of soft and hard tissues; therefore its study can be useful for undergraduate students.

\section{Electrospinning procedure}

Electrospinning is a commonly used technique for the fabrication of fibers at nanoscale level, this procedure uses an electrical field for the formation of the nanofibers, which can be made of polymeric, metallic, ceramic or composite solutions. 


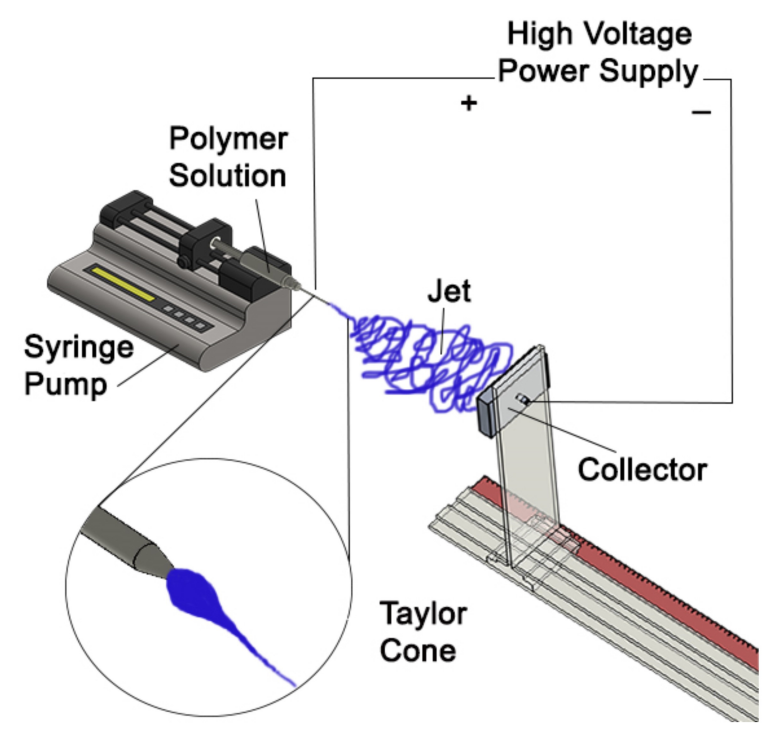

Figure 1: Basic configuration of a electrospinning device.

The electrospinning process comprises of three stages:

First the syringe pump and the power supply are switched on and voltage is adjusted from $5 \mathrm{kV}$ to $50 \mathrm{KV}$ depending on the dielectric constant of the solvent and the viscosity of the solution. The electric potential charges the drop of polymer solution formed at the tip of the needle, and the induced charges are evenly distributed. The jet forms when the potential overcomes the surface tension of the drop.

A schematic of an electrospinning device is shown in figure 1. Voltage is applied between the needle tip of the injector and the collector, charging the polymer solution, which forms a jet that is electrically attracted and deposited as solid fibers in the collector [3-6].

The electrostatic field distorts the drop into a cone at the tip of the needle, named "The Taylor cone" [7]. The polymeric solution emerges from the needle's tip and forms a droplet. The charged needle transfers its electrical energy to the bead. At a specific voltage, the droplet will change its morphology as it gets pulled towards the collector, creating the Taylor cone [4]. The geometry of the cone is ruled by the ratio of the solution's surface tension to the forces of electrostatic repulsion and the field strength, E. During stage 1, as the voltage surpasses the threshold voltage $(\sim 6 \mathrm{kV})$, the strength of $\mathrm{E}$ field and electrostatic repulsions in the polymeric solution grow and overcome the opposing force of the solution's surface tension, finally resulting in the forced ejection of a stable liquid jet from the needle. In stage 2 , as the voltage is increased beyond the threshold voltage $(>6 \mathrm{kV})$ to near $11 \mathrm{kV}$, the stable jet destabilizes. The liquid jet is ejected from the tip of the cone. As the jet travels to the collector it stretches and loops as the solvent is evaporated.

The elongation of the polymer fiber is due to synchronized but separate events: the solvent evaporating from the polymer, which solidifies the fiber, and the charges within the polymer repelling each other. The result is a drastic reduction in the diameter of the fiber with a significant increase in length [5]. The stage 2 is the boundary between the stable and whipping jet. During stage 3, nanofibers are formed through the elongation, evaporation, and deposition of the flogging jet. Finally, the fibers attracted towards the grounded collector due to the attraction of opposite charges and are deposited onto its surface. Although most of the solvent will evaporate as the jet whips through the air, residues will evaporate upon deposition [6].

\section{Electrospun nanofibers applications}

Electrospun scaffolds have several advantages for tissue engineering: suitable topography (3D structure, porosity, alignment and nanoscale size), ability of encapsulating interesting chemical compounds (pharmaceutical drugs, growth factors), local sustained release of such compounds and surface functionalization (attachment of functional groups) (fig. 2). Materials used for tissue engineering must be biocompatible, they can be natural or synthetic biodegradable polymers and blends with bioactive organic or inorganic materials [8]. 
Electrospun fibers can be used to fabricate artificial blood vessels. Aligned nanofibers of biodegradable poly (L-lactidco-caprolactone) have been evaluated as a potential scaffold for blood vessel engineering through culturing human coronary artery smooth muscle cells [8].

One of the challenges is achieving enough cellular infiltration into the electrospun fibrous scaffolds. This was solved in part by combining electrospinning and electrospraying to fabricate cellmicrointegrated blood vessel constructs that were highly cellularized with smooth muscle cells (SMCs) in the interior of the walls. These conduits were shown to be biocompatible, stronger and possess compliance values similar to native blood vessels [8].

Tissue engineering can work together with stem cell biology and gene therapy to create innovative strategies for blood vessel regeneration. For example, a vascular graft has been fabricated by seeding genetically engineered mesenchymal stem cell (MSCs) onto a tubular scaffold of electrospun poly (propylene carbonate) and the seeded cells were incorporated into the microstructure of the graft to form a 3D cellular network [8].

Few reports on the construction of a teaching-focused laboratory electrospinning device are known in literature, commercial devices are expensive for educational and

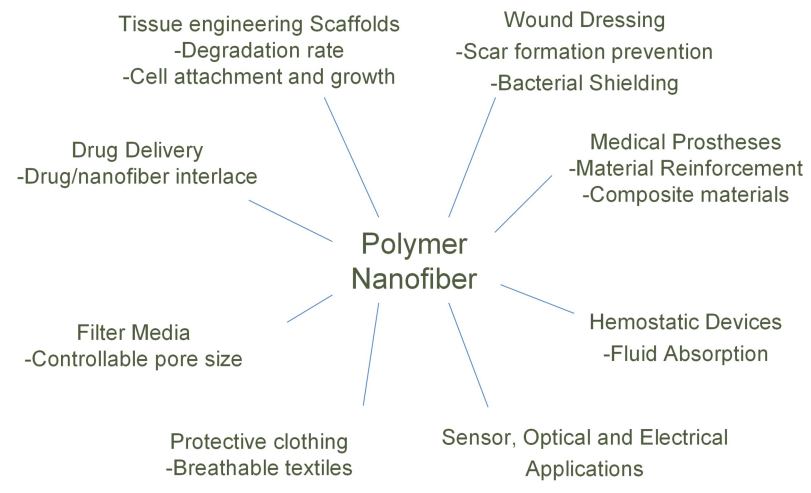

Figure 2: Applications of electrospun nanofibrous scaffolds. training purposes. The price of a singlenozzle electrospinning machine like those typically used in a laboratory may range from $\$ 17,000$ to $\$ 60,000$ USD, according to Abdulah Aslamaci of NanoFMG [9]. Equipment for mass-producing electrospun fibers can range from 170, 000to300,000 USD. Prices vary depending on brand and market fluctuations. However, each university may construct their own laboratory devices. Machines able to electrospin fibers can be easily constructed from simple lab supplies for much less, assuming a high-voltage power source is available. For example, the Materials Research Institute (Instituto de Investigaciones en Materiales) of the Universidad Nacional Autónoma de Mexico fabricated their own electrospinning devices, collectors and accessories, giving the group of researchers and students the ability to innovate scaffolds for tissue engineering [10].

\section{METHODOLOGY}

\section{Materials}

Poly (vinyl alcohol) PVA $(\mathrm{Mw}=13,000$ - 23,000, $87 \%$ - $89 \%$ hydrolyzed from ALDRICH), acetic acid, distilled water, was used as purchased. Acrylic sheet was obtained from a local hardware store.

\section{Electrospinning chamber construction}

An electrospinning chamber was built using an acrylic sheet $(0.5 \mathrm{~cm}$ thick $)$. First, the sheet was divided into six parts with a table saw using a saw blade suitable for plastic cutting. Then, using a milling machine (Birmingham BPS1649-C) the acrylic parts had their dimensions adjusted (four acrylic sheets measured $79 \mathrm{~cm}$ length and the other two measured $50 \mathrm{~cm}$ length).

A $60 \times 29 \mathrm{~cm}$ rectangular hole was cut at the center of one of the $79 \times 51 \mathrm{~cm}$ sheets to create an acrylic access window, which was covered with a hinged rectangular door $(61 \times 30 \mathrm{~cm})$. In addition, a hole $(1.5 \mathrm{~cm}$ dia. $)$ was drilled in the center of one of the $50 \times 50$ 
cm sheets in order to insert a rubber stopper intended to be punctured by the needle under sealed conditions.

The rectangular chamber was assembled with the aid of corner clamps, aligning the edges before applying acrylic cement and gluing the pieces together. To ensure stability, three acrylic 90o "L" reinforcements were placed equally spaced along the inner edges of the chamber. Two acrylic hinges were placed near the edges of the door and glued in place with acrylic cement. To lock the door two latches were fixed under the door. The door was sealed using adhesive foam along the edges. For preventing injuries, and to protect the chamber from damage, plastic protectors were glued around the outside edges of the chamber.

\section{Collector}

Different types of simple collectors can be constructed for obtaining fibers and scaffolds of different characteristics, such as orientation and form. The collector's base was built using the remaining pieces of acrylic. Collectors were designed with SolidWorks software and made out of aluminum and copper. Their function was to collect the fibers randomly, while being static.

\section{Syringe pump and power supply}

A single syringe pump (World Precision Instruments (WPI) SP120PZ) and a power supply (Spellman's Bertan Brand High Voltage Module, Model: 605C - 200P) were used (fig. 4).

\section{Validation of electrospinning setup functionality \\ PVA dissolution}

Two $50 \%$ (w/v) PVA solutions were prepared at $80^{\circ} \mathrm{C}$ under constant stirring for one hour using distilled water as a solvent in the first one (PVA1) and a 2\% acetic acid solution in the second (PVA2). These solvents yielded successful PVA nanofiber production [10]. Once dissolved, the solutions were let to settle overnight to remove bubbles.

\section{PVA electrospinning}

A plastic syringe (22G) was loaded with the PVA solution removing the bubbles; two tests were conducted. The first one at $10 \mathrm{~cm}$ distance from the tip of the needle to the collector position, $13 \mathrm{kV}$ of applied voltage and $0.2 \mathrm{ml} / \mathrm{h}$ of injection rate of the solution (PVA1). The second one at $15 \mathrm{~cm}, 20 \mathrm{kV}$ and $0.2 \mathrm{ml} / \mathrm{h}$ (PVA2), both samples were left one hour in the electrospinning system.

\section{Scanning Electron Microscopy (SEM)}

The morphology, porosity and diameter of PVA fibers were determined with SEM; a small section of the fiber mat was placed on a SEM sample holder and sputter-coated with gold. A JEOL JSM 7600F emission field microscopy with an accelerating voltage of 20 KV was employed for the SEM photographs.

\section{Fiber diameter and porosity of the scaffolds}

The average diameter of the fibers and the porous area of the membranes were determined from SEM micrographs with the aid of a software (Image J).

The procedure for measuring the diameter using ImageJ was: 1) load the SEM image into the software; 2) select the measuring tool; 3) set the scale, establishing a relation between the unit of measure and the pixels; 4) measure the fiber diameter (at least 30 fibers were measured taken from first-plane, continuous fibers); 5) calculate the mean diameter, standard deviation and porous area by using a Microsoft Excel data analyzing software).

A similar procedure was used for determining the porous area (empty spaces) using ImageJ (steps 1 to 3 ). The pores were differentiated by color and a particle analyzer 
tool was used to determine the percentage between one color and the other.

\section{RESULTS AND DISCUSSION}

A fully functional device for the production of nanofibrous scaffolds was built. The scaffolds intend to simulate the extracellular matrix of living tissues; in order to incorporate laboratory sessions for the biomaterials curriculum or syllabus laboratory equipment of tissue engineering for undergraduate students. This device will serve as a didactic prototype for fabricating fibrous scaffolds. In this course the students will learn how different types of materials (ceramics, polymers, metals and composites) interact with the human body when implanted; this includes their chemical, biological and mechanical properties. The electrospinning device allowed the incorporation of a series of laboratory experiments to create polymer scaffolds which could be used for implants, wound dressing, drug delivery, filtration, etc. In order to successfully prepare nanofibrous scaffolds, students should study and practice the correlation between the solution and processing parameters with the fiber quality. They will learn the effects of the dielectric constant of the solvent, molecular weight of the polymer, viscosity, the inner diameter of the needle, potential difference, needlecollector distance, chamber temperature and relative humidity on the scaffold's properties and the fiber characteristics.

Figure 3 shows a bioengineering student working on the construction of the electrospinning cabinet (assisted by a mechanical workshop engineer). The purpose of the cabinet, besides working under safe operating conditions, is to control temperature and relative humidity during electrospinning, as it has been reported, these parameters affect the morphology of the fibers $[12,1]$.
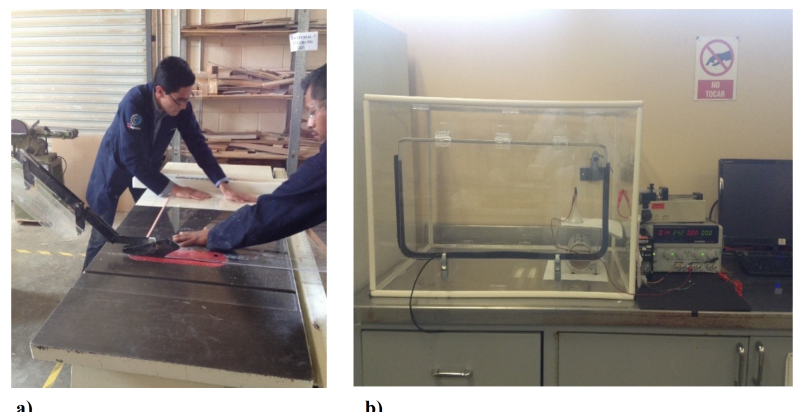

b)

Figure 3: Acrylic Cabinet of the Electrospinning device. a) Bioengineering student cutting an acrylic sheet. b) The assembled acrylic cabinet.

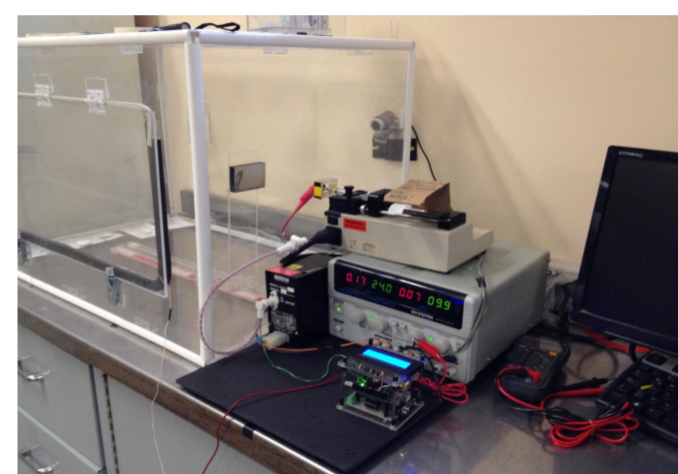

a)

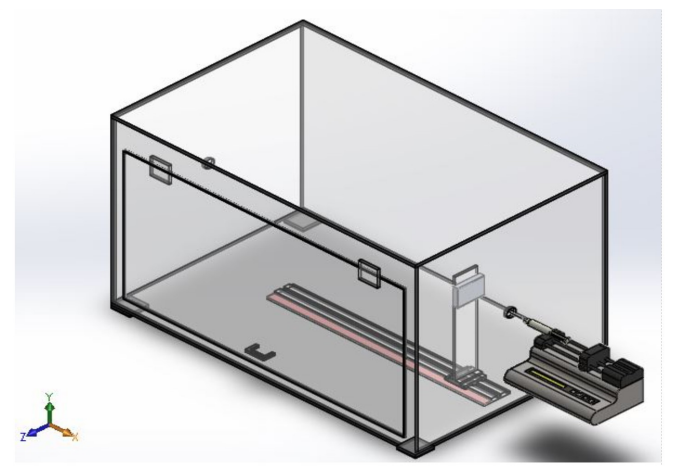

b)

Figure 4: The Electrospinning device. a) High voltage power supply. b) CAD representation of the chamber and syringe pump. 


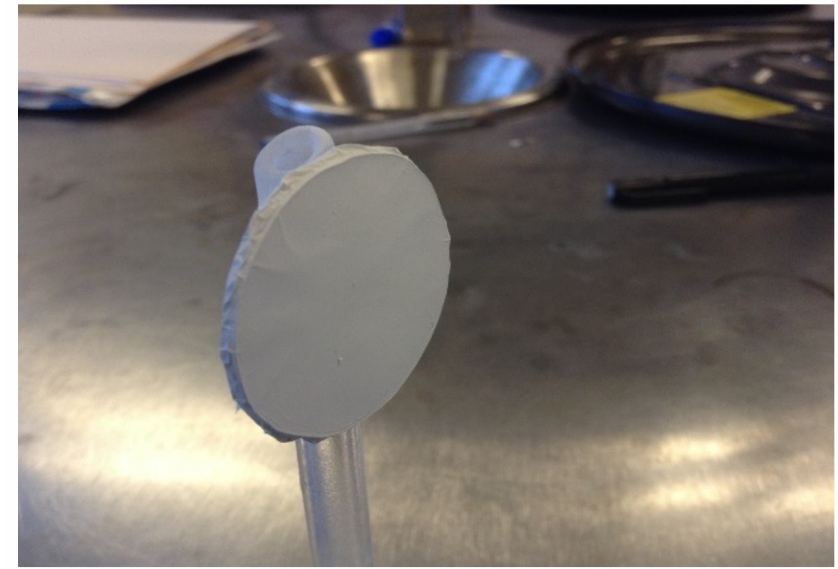

a)

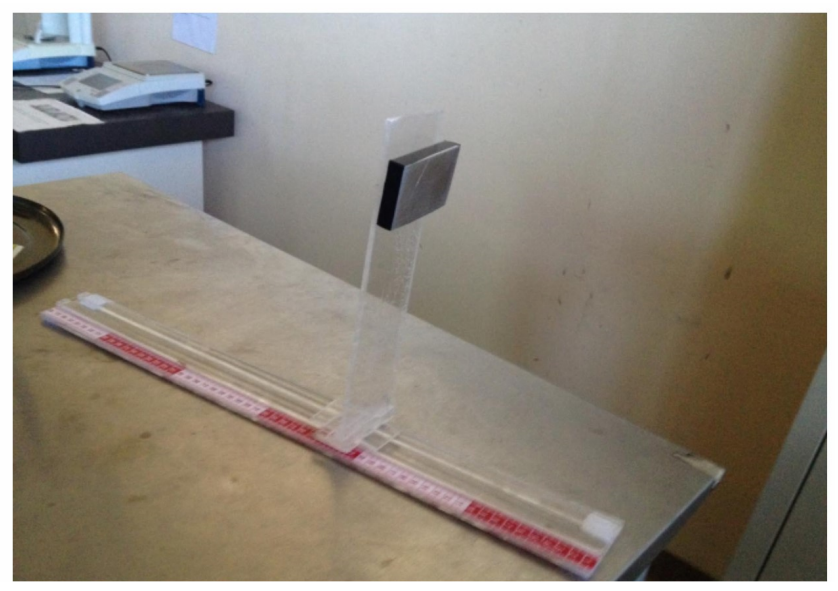

c)

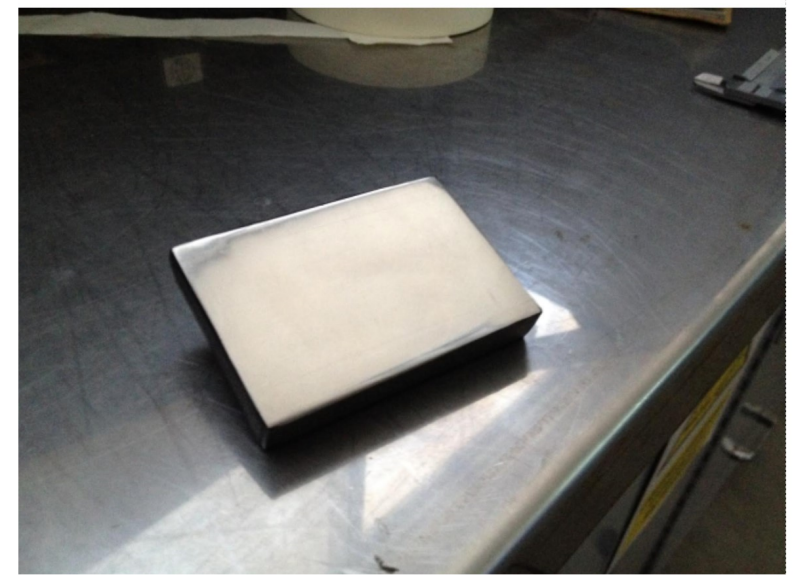

b)

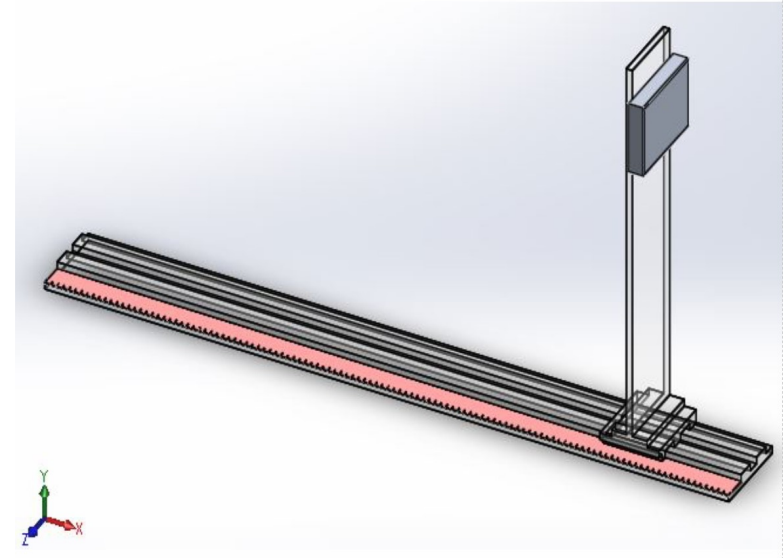

d)

Figure 5: Fibrous Scaffolds Collectors. a) Copper round collector (Covered in aluminum foil for retrieving the fibrous mats). b) Aluminum rectangular collector. c) Accessory to hold the collector and adjust the distance between the collector and the needle tip. d) Collector accessory CAD model.

\section{Collector plate characteristics}

The surface of the collector must be a good electric conductor such as copper or aluminum; the students fabricated two aluminum plates, one is a rectangle $(7.4 \mathrm{~cm}$ length, $4.9 \mathrm{~cm}$ height, $1.1 \mathrm{~cm}$ thick) and another has a circular shape $(2.8 \mathrm{~cm}$ dia.). In addition, a collector accessory base was designed to hold the collector in place and allow the adjustment of the distance between the collector and the needle tip of the syringe (fig. 5).

\section{Electrospinning device test results}

Two PVA solutions (PVA1 and PVA2) were used to prepare electrospun scaffolds and to validate the functionality of the equipment. The SEM images (fig. 6) depict the random arrangement of the fibers, porosity, diameter and regularity of fiber diameter along the fibers. It can be seen that PVA1 fibers show smaller diameter than those of PVA2. The factors affecting the diameter are the solvent dielectric constant, the needle tip-collector distance and the applied voltage. 

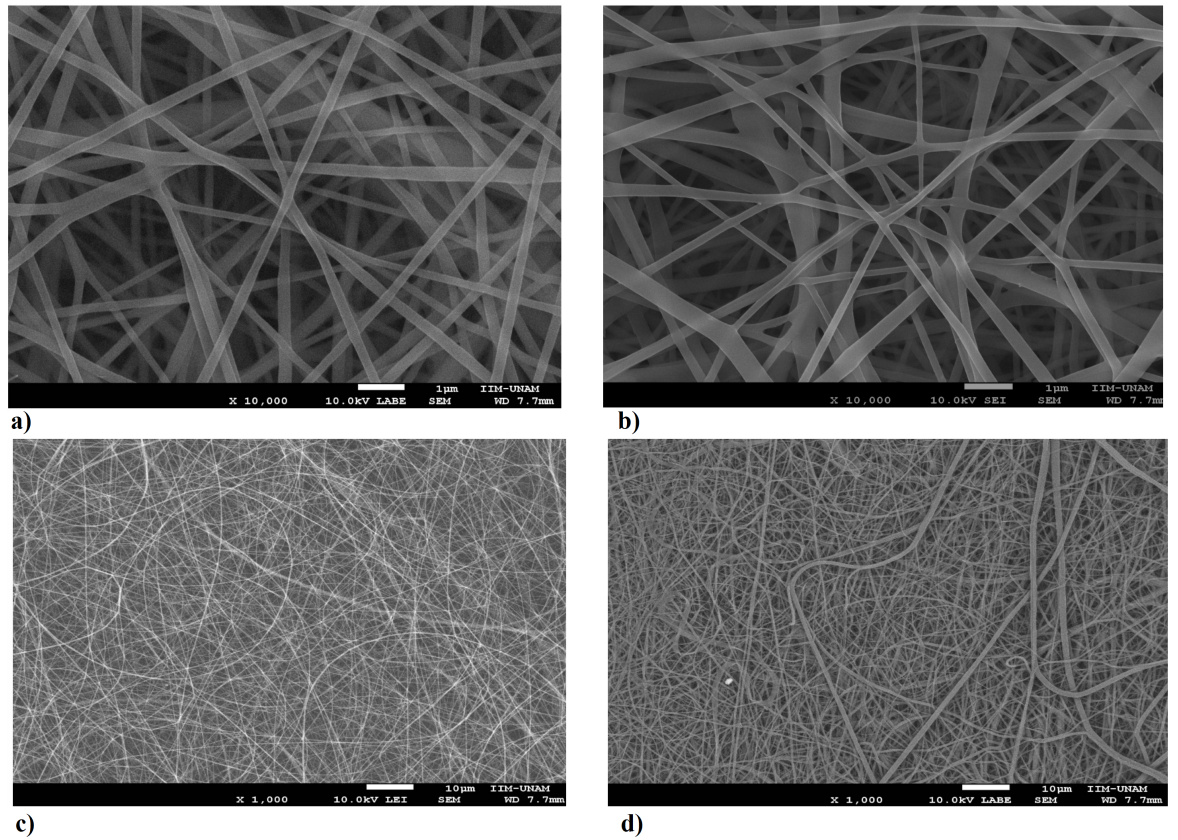

Figure 6: SEM images of two PVA electrospun scaffolds: a) PVA1 10,000 x (1 $\mu \mathrm{m})$, b) PVA2 10,000 x $(1 \mu \mathrm{m})$, c) PVA1 1,000 x $(10 \mu \mathrm{m})$, d) PVA2 1,000 x $(10 \mu \mathrm{m})$.

Table 1: Process parameters and characteristics of two PVA random nanofiber scaffolds

\begin{tabular}{cccccc}
\hline Sample & Solvent & Voltage & Collector distance & Average nanofiber diameter & $\%$ porosity \\
\hline PVA1 & $2 \%$ Acetic acid & $13 \mathrm{kV}$ & $10 \mathrm{~cm}$ & $216 \pm 50 \mathrm{~nm}(103-322 \mathrm{~nm})$ & $53.985 \%$ \\
PVA2 & Distilled water & $20 \mathrm{kV}$ & $15 \mathrm{~cm}$ & $260 \pm 100 \mathrm{~nm}(143-435 \mathrm{~nm})$ & $52.335 \%$ \\
\hline
\end{tabular}

Table 1 compares the characteristics of two scaffolds prepared under different conditions (solution and electrospinning parameters). The PVA1 scaffold ( $2 \%$ acetic acid, $13 \mathrm{KV}$ voltage and $10 \mathrm{~cm}$ distance) yielded thinner fiber diameter and greater porosity than PVA2.

\section{Comparison between other techniques for scaffolds fabrication}

There are several methods for fabricating nanostructured scaffolds for tissue engineering: solvent casting, particulate leaching, porogen leaching, gas foaming, membrane lamination, electrospinning, melt molding, fiber meshing, phase separation, fiber bonding, rapid prototyping (RP), freeze-drying and self-assembly [14]. PLLA, PLGA, PGA/PLLA, silk, PLGA-g-HA, Chitosan/PCL, Collagen/PCL, between others biopolymers have been used for fabricating nanofibers by the electrospinning method, these nanofibers presented an average diameter between 400-1100 nm, with an average porosity of the scaffolds of $80 \%-95 \%$. In the case of the phaseseparation method, there are reports that show the use of PLLA/HAP, PLGA and Chitosan, with a fiber diameter of $50-500 \mathrm{~nm}$, and a porosity of $60 \%-98 \%$. Also reported are Chitosan/PLLA, Collagen/GAG and Gelatin/PHEMA scaffolds using a freezedrying method, obtaining a diameter of the fibers of $50-450 \mathrm{~nm}$, with $30 \%-80 \%$ porosity. Finally, different peptides scaffolds have been 
made by a self-assembly method, resulting fiber with diameters of $5-100 \mathrm{~nm}$, with $80 \%$ $90 \%$. [15].

All the scaffolding fabrication methodologies have their limitations and advantages [14]. The self-assembly method yields the smaller fibers diameters; however it is useful only for natural biopolymers (phospholipids, proteins, etc.) and cells, which precisely have selfassembly features, and the procedure is expensive [16]. Solvent casting/particulate leaching have the advantage of controlling over porosity, pore size and crystallinity, but it renders limited mechanical properties, residual solvents and porogen material [17]. Gas foaming is a method free of harsh organic solvents, in can control the porosity and pore size, despite this, the process produces limited mechanical properties and inadequate pore interconnectivity [18]. Electrospinning is an economic and useful method to prepare scaffolds at laboratory, pilot and industrial level, provided the adequate control of solution and processing parameters.

\section{Limitations of our electrospinning device}

The described electrospinning device is of simple construction and it can be modified easily; but it has some limitations that can be easily overcome: The power supply generates a voltage that reaches only up to $20 \mathrm{KV}$, the collectors are static and the area of the scaffolds depend on collector's dimensions. The minimum diameter of the fiber is physically bound by the diameter of the needle. At the moment, the temperature and relative humidity depend on the environment. Although under the present conditions the device is useful for didactic purposes, it could be easily upgraded for fine research purposes.

\section{CONCLUSIONS}

The electrospinning prototype is a useful and affordable device for educational purposes; it is $95 \%$ cheaper than those commercially available. The device is currently used for the teaching-learning process of scaffolds fabrication in the laboratory sessions of the biomaterials course.

\section{ACKNOWLEDGEMENT}

The authors thank to "Maestría y Doctorado en Ciencias Químicas e Ingeniería, Universidad Autónoma de Baja California (MYDCI-UABC)".

\section{REFERENCES}

1. McCallus R. The Effects of Bioengineering on the Medical World. https://infogr.am/Bioengineering-inMedicine-mccallusrs_1365786946.

2. Tirrell DA. Biomaterials: Important Areas for Future Investment. National Science Foundation Workshop. 2012.

3. Malshe H, Malshe AP, Jiang W. "Design, Fabrication and Testing of an Electrospinning Apparatus for the Deposition of PMMA Polymer for Future Biomedical Applications". Inquiry, vol. 12, pp. 70-76, 2011.

4. Vonch J, Yarin A, Megaridis, C.M. "Electrospinning: A study in the formation of nanofibers". J Undergrad Res, vol. 1, pp. 1-6. 2007.

5. Taylor G. "Disintegration of water drops in an electric field". Proceedings of the Royal society of London series A, Mathematical and Physical, vol. 280 (1382): pp. 383-397, 1964.

6. Ramakrishna S, Fujihara Teo WE, Lim TC, Ma Z. "An Introduction to electrospinning and nanofibers. Electrospinning and Nanofibers". National University of Singapore. World scientific Publishing co. Pte. Ltd. ISBN: 978-981-256-415-3. 2005. 
7. Xie J, Xia Y. "Electrospinning: An Enabling Technique for Nanostructured Materials". Mater Matters, vol. 3, no. 1, pp. 19. 2008.

8. Abdullah Aslamaci NanoFMG http://www.nanofmg.com

9. (a) Gómez-Pachón EY, MontielCampos R, Moreno-Rondón EV, VeraGraziano R. "Diseño de un equipo de Electrospinning para la Fabricación de Andamios de Nanofibras para Aplicaciones Biomédicas". Memorias del XVI Congreso Internacional Anual de la SOMIM. Monterrey, Nuevo León, México. ISBN: 978-607-95309-3-8. 2010.

(b) Gómez-Pachón EY, SánchezArévalo FM, Sabina FJ, Maciel-Cerda A, Montiel-Campos R, Batina N, Morales-Reyes I, Vera-Graziano R. "Characterization and modelling of the elastic properties of poly(lactic acid) nanofibre scaffolds". J Mater Sci, vol. 48, pp. 8308, 2013.

10. Sajeev US, Anand KA, Menon D, Nair S. "Control of nanostructures in PVA, PVA/chitosan blends and PCL through electrospinning". Bulletin Mater Sci, vol. 31, pp. 343-351. 2010.

11. Vera-Graziano R, Maciel-Cerda A, Moreno-Rondon EV, Ospina A, GomezPachon EY. Mater Res Soc Symp Proceed, pp. 1373, 2012.

12. (a) Villarreal-Gómez LJ, Vera-Graziano R, Vega-Ríos MR, Pineda-Camacho JL, Almanza-Reyes H, Mier-Maldonado PA, Cornejo-Bravo JM. "Biocompatibility evaluation of electrospun scaffolds of poly (L-Lactide) with pure and grafted hydroxyapatite". J Mex Chem Soc, vol. 10, no. 584, pp. 435-443, 2014.

(b) Villarreal-Gómez LJ, Vera-Graziano R, Vega-Ríos MR, Pineda-Camacho JL, Almanza-Reyes H, Mier-Maldonado PA, Cornejo-Bravo JM. " In vivo biocompatibility of dental scaffolds for tissue regeneration". Adv Mater Res, vol. 3, pp. 191-195. 2014.

13. Subia B, Kundu J, Kundu SC. "Biomaterial scaffold fabrication techniques for potential tissue engineering applications". Tissue Engineering INTECH. Chapter 7, pp. 141-157, 2010.

14. Lu T, Li Y, Chen T. "Techniques for fabrication and construction of three-dimensional scaffolds for tissue engineering". Int J Nanomed, vol. 8, pp. 337-350, 2013.

15. Zhao J, Han W, Chen H, Tua M, Zenga R, Shic Y, Chab Z, Zhou C. "Preparation, structure and crystallinity of chitosan nanofibers by a solid-liquid phase separation technique". Carbohydr Polym. Vol. 83, pp. 15411546. 2011.

16. Ma PX. "Biomimetic materials for tissue engineering". Adv Drug Deliv Rev., vol. 60, pp. 184-98, 2008.

17. Ikada Y. Scope of tissue engineering In: Tissue Engineering: Fundamental and Applications, Ikada Y. (Ed.). PP 29, Academic press, USA. 2006. 